\title{
Effect of asthma severity on symptom perception in childhood asthma
}

\author{
A.L.B. Cabrall, 2,3 , \\ G.M. Conceição ${ }^{3}$, \\ P.H.N. Saldiva ${ }^{3}$ \\ and M.A. Martins ${ }^{2}$
}

\author{
${ }^{1}$ Divisão de Pediatria, Hospital Darcy Vargas, São Paulo, SP, Brasil \\ Departamentos de ${ }^{2}$ Clínica M édica and ${ }^{3}$ Patologia, Faculdade de Medicina, \\ Universidade de São Paulo, São Paulo, SP, Brasil
}

\begin{abstract}
Correspondence
M.A. Martins

Departamento de Clínica Médica

FM, USP

Av. Dr. Arnaldo, 455, Sala 1216

01246-903 São Paulo, SP

Brasil

Fax: +55-11-3083-0827/3085-0992

E-mail: mmartins@usp.br

Research supported by CN Pq, FAPESP and PRONEX-MCT.
\end{abstract}

Received June 11, 2001

Accepted January 2, 2002

\section{Abstract}

Individual ability to perceive airway obstruction varies substantially. The factors influencing the perception of asthma are probably numerous and not well established in children. The present study was designed to examine the influence of asthma severity, use of preventive medication, age and gender on the association between respiratory symptoms (RS) and peak expiratory flow (PEF) rates in asthmatic children. We followed 92 asthmatic children, aged 6 to 16 years, for five months. Symptom scores were recorded daily and PEF was measured twice a day. The correlations among variables at the withinperson level over time were analyzed for each child and for the pooled data by multivariate analysis. After pooling the data, there was a significant $(\mathrm{P}<0.05)$ correlation between each symptom and $\mathrm{PEF}$; $60 \%$ of the children were accurate perceivers (defined by a statistically significant correlation between symptoms and PEF across time) for diurnal symptoms and $37 \%$ for nocturnal symptoms. The accuracy of perception was independent of asthma severity, age, gender or the use of preventive medication. Symptom perception is inaccurate in a substantial number of asthmatic children, independently of clinical severity, age, gender or use of preventive medication. It is not clear why some asthmatic patients are capable of accurately perceiving the severity of airway obstruction while others are not.

\section{Introduction}

There is general agreement that symptom scores are unreliable as the only index of asthma severity because they are subjective, suffer psychological influences, vary according to lifestyle and may be reduced by the use of beta 2 agonists (1-3). Studies designed to assess asthma severity often demonstrate only a weak correlation between the degree of airway obstruction and the magnitude of asthma symptoms (1-3).

Inaccuracy of symptom perception can occur within two extremes of a spectrum:

\section{Key words}

- Asthma

- Asthma severity

- Pulmonary function tests

- Symptom perception

- Childhood asthma from blunted to overperception of symptoms. Blunted perception of airway obstruction in some patients may lead to underestimation of the severity of asthma, resulting in undertreatment and an increased risk of experiencing an acute, life-threatening asthma attack. On the other hand, overperception of airway obstruction may lead the patients to repeatedly increase their medications for symptoms, which are unrelated to changes in objective measures. Inaccurate perception of symptoms may result in excessive medication and hospitalization, unwarranted illness behavior and negative emotions (4). 
In an attempt to overcome these problems, the use of objective measures of airflow obstruction has been advocated by several clinical guidelines (5-7). However, the ability to use a peak flow meter and the adherence to peak flow monitoring in children with asthma also require consideration. It is possible that not all asthmatics benefit from objective measures of airway obstruction, since the "good perceiver" group could be adequately followed by the assessment of symptoms. Properly characterizing the "good perceivers" may simplify the follow-up of some asthmatic patients, helping them evaluate their symptoms, their importance and the appropriate action to take when their condition deteriorates.

Most studies of asthma perception have been conducted on adult patients $(1,3,8,9)$ and only a few have been performed on children in natural environments $(2,10,11)$. Factors that might influence the perception of asthma symptoms such as gender, age, sex, asthma severity and use of medications have not been fully addressed in children.

The present study was designed to determine if the perception of airflow obstruction during spontaneous changes in the severity of airway obstruction depends on asthma severity, sex, age or use of preventive medication in children with asthma.

\section{Patients and Methods}

\section{Study subjects}

The Institutional Review Board approved the protocol and parents gave informed written consent for their children. The data for this study were obtained from a group of 92 asthmatic children aged 6 to 16 years, who had been admitted to a five-month program for asthmatic children at a center for physical activities. All children had a physician diagnosis of asthma. These children were followed from May to September, corresponding to the autumn and winter seasons of the southern hemisphere. During this period upper respiratory infections are frequent and the likelihood of variations in peak expiratory flow (PEF) rate is greater even for children with mild asthma.

There was no selection of patients, since all patients who manifested the desire to adhere to the study protocol were accepted. Patients were classified as having mild $(\mathrm{N}=$ $24)$, moderate $(\mathrm{N}=34)$ and severe asthma $(\mathrm{N}$ $=34$ ) according to the International Consensus Report on Diagnosis and Treatment of Asthma (5) based on the replies to a questionnaire administered by an interviewer and on lung function tests. The questions inquired about the frequency and intensity of symptoms, frequency of exacerbations, need for hospitalization, and medications used in the previous 12 months.

Some children were taking preventive medications (nedocromil, cromoglycate, inhaled beclomethasone) that were continued throughout the 5-month study; for episodes of exacerbations they received oral steroids.

\section{Study design}

The children came to the center twice a week for a physical rehabilitation program. They also received lessons about asthma, its symptoms, environmental control measures, treatment and control in small groups according to age. The parents received the same lessons. During each physical activity session, the children were asked to estimate their breathlessness and measure their PEF before and after physical activities. As part of the educational program, the children and their parents were strongly encouraged to fill out a daily card on which they recorded the presence of daytime asthma symptoms (cough, breathlessness and wheezing) and nighttime awakenings for symptom assessment (as recommended by the International Consensus Report on Diagnosis and Treatment of Asthma) (5). The recorded symptoms - cough, breathlessness and wheezing - 
were scored individually using a binary code ( 0 , absence, or 1 , presence). The coding of symptoms was computed for the day and night. An additional estimator of symptom severity was obtained by summing each individual code of symptoms recorded for the day period, which in our case ranged from 0 (minimum) to 3 (maximum). PEF rate in the morning (before the use of any medication) and in the evening were also recorded using an Assess PEF meter (Health Scan, Cedar Grove, NJ, USA). The importance of recording symptoms and PEF was stressed during the classes and the diaries were used to teach the patient and their parents to recognize asthma control and early signs of an exacerbation. Instructions were also given about the correct technique for obtaining a PEF reading. The best of three attempts was recorded on each occasion. The diaries were completed with the help or under the supervision of the parents. The best PEF was considered to be the maximal PEF reading achieved at any time during the study period. The use of medication was also recorded on the diary card.

\section{Data analysis}

The correlation between symptoms and peak flow was calculated on a daily basis using the morning peak flow measurement. We used morning PEF since Reddel et al. (12) showed that the minimum morning prebronchodilator PEF over a week was the most useful index in the management of asthma. In addition, morning measurements of PEF had a smaller number of missing points in our series.

The children were classified into groups according to asthma severity (mild, moderate and severe), three age ranges (6 to 9 years, 10 to 11 years, and 12 to 16 years), gender, and use of preventive medication (yes or no).

In the first approach we examined the within-person correlations between symp- toms and PEF for each patient $(\mathrm{N}=92)$ separately to identify and account for individual differences in symptom perception accuracy. Individual multiple regressions of each symptom on the morning PEF were performed during each patient's assessment, controlling for up to third-order autocorrelation using a generalized least-squares approach. In order to model a possible variation in PEF along the study period due to non-observed factors (such as non-linear change in age or height), a time variable (assuming values from one to the number of days of follow-up) as well as the squared time variable was included in the model.

Children showing no variability of the symptom under study were excluded from the respective analysis (Figure 1). A significant correlation between symptoms and PEF was defined by a negative coefficient, with the level of significance set at 0.05 . Patients showing a significant correlation were considered to be accurate perceivers. The proportion of individuals exhibiting a significant correlation was compared across the groups (defined by asthma severity, age, gender and use of preventive medication) by the chi-square test.

In the second approach we performed regression models similar to those described above but using all data pooled together. The dependent variable was the morning PEF and the independent variables were the studied symptom, time, and squared time, plus a dummy variable for each child in order to model the variability in PEF due to differences among children. This model was initially adjusted for all the children and then for each group of patients described above.

These analyses were performed using the AUTOREG procedure of the SAS statistical package (SAS Institute Inc., Cary, NC, USA).

\section{Results}

Ninety-two children provided a mean of 88 days of observations (range: $30-152$ days). 
Only 48 (52\%) children had at least 90 consecutive days of observation, suggesting that the adherence to PEF monitoring decreases with time. There were no significant differences between the groups of children that provided full and missing data with respect to asthma severity, age, sex and the number of accurate perceivers. The clinical characteristics of the children studied are presented in Table 1.

Figures 1-4 present the percentage of children exhibiting a significant correlation between perception of symptoms and PEF values according to asthma severity, gender, age or prescription of preventive medications. A significant correlation was observed in $37.2,37.8,36.6$ and $37.1 \%$ of the children, for cough, breathlessness, wheezing and nocturnal symptoms, respectively. When the diurnal symptoms were considered together, the percentage of significant correlations increased to $59.8 \%$.

Figure 1 shows the percentage of children exhibiting a significant correlation between symptoms and PEF, divided into three groups according to asthma severity. We did not observe a significant influence of asthma severity on the percentage of children who showed a significant correlation between PEF values and cough ( 86 children studied, $\mathrm{P}=$ $0.09)$, breathlessness $(\mathrm{N}=82, \mathrm{P}=0.52)$, wheezing $(\mathrm{N}=82, \mathrm{P}=0.74)$, nocturnal symptoms $(\mathrm{N}=70, \mathrm{P}=0.10)$ or total diurnal symptoms (cough, breathlessness and wheezing, $\mathrm{N}=87, \mathrm{P}=0.51)$.

We did not observe a significant influence of gender on the percentage of children who showed a significant correlation between symptoms and PEF values (Figure 2). Although more girls tended to have accurate perception, these differences did not reach statistical significance $(\mathrm{P}=0.12,0.12$ and 0.24 for cough, breathlessness and wheezing, respectively). Furthermore, there was a similar percentage of boys and girls exhibiting a significant correlation between daytime symptoms and PEF $(\mathrm{P}=0.89)$ and between nocturnal symptoms and PEF $(\mathrm{P}=$ 0.39 ).

The influence of age on perception of airway obstruction can be observed in Figure 3. We did not observe any significant effect of age on the percentage of children with a significant correlation between PEF and cough $(\mathrm{P}=0.90)$, breathlessness $(\mathrm{P}=$ $0.54)$, wheezing $(P=0.96)$, total diurnal symptoms $(\mathrm{P}=0.45)$ or nocturnal symptoms $(\mathrm{P}=0.45)$.

Figure 4 shows the data concerning the influence of the use of preventive medicine (nedocromil, cromoglycate or beclomethasone) on the percentage of children who presented a significant correlation between symptoms and PEF values. There was a ten-

Table 1. Clinical characteristics of the children who participated in the study.

\begin{tabular}{lcccc}
\hline Asthma severity & Mild & Moderate & Severe & Total \\
\hline $\mathrm{N}$ & 24 & 34 & 34 & 92 \\
Mean age (years) & $10 \pm 3$ & $9 \pm 2$ & $9 \pm 2$ & $9 \pm 3$ \\
Mean PEF (\% predicted) & $0.80 \pm 0.06$ & $0.76 \pm 0.08$ & $0.75 \pm 0.10$ & $0.77 \pm 0.10$ \\
Percent days with cough & $38 \pm 32$ & $44 \pm 29$ & $44 \pm 28$ & $42 \pm 29$ \\
Percent days with breathlessness & $16 \pm 22$ & $23 \pm 23$ & $27 \pm 24$ & $23 \pm 23$ \\
Percent days with wheezing & $21 \pm 21$ & $23 \pm 22$ & $40 \pm 31$ & $29 \pm 27$ \\
Percent days with nocturnal symptoms & $10 \pm 16$ & $13 \pm 20$ & $22 \pm 28$ & $16 \pm 23$ \\
Percent days with any symptoms & $43 \pm 34$ & $54 \pm 31$ & $57 \pm 28$ & $52 \pm 31$ \\
Percent days with PEF <80\% predicted & $42 \pm 26$ & $58 \pm 30$ & $62 \pm 29$ & $55 \pm 29$ \\
Percentage of children taking preventive & 4.2 & 44.1 & 73.5 & 44.6 \\
$\quad$ medications & $(\mathrm{N}=1)$ & $(\mathrm{N}=15)$ & $(\mathrm{N}=25)$ & $(\mathrm{N}=41)$ \\
\hline
\end{tabular}

Data are reported as means \pm SEM. PEF, peak expiratory flow. 
dency for more children who used preventive medications to exhibit a significant correlation between symptoms and PEF, although these differences did not reach statistical significance $(\mathrm{P}=0.08,0.16,0.14,0.08$ and 0.24 for cough, breathlessness, wheezing, total diurnal symptoms and nocturnal symptoms, respectively).

When the correlation coefficients between each asthma symptom and PEF values were calculated after pooling the data across patients and observations and adjusting for autocorrelation, a significant correlation was observed between each symptom and PEF $(\mathrm{P}<0.05)$. The reduction of peak flow measures associated with the presence of symptoms were $-11.14 \mathrm{l} / \mathrm{min}$ for cough, -14.47 $1 /$ min for wheezing, $-13.21 \mathrm{l} / \mathrm{min}$ for breathlessness and $-14.10 \mathrm{l} / \mathrm{min}$ for nocturnal symptoms. The coefficients calculated for each group of patients according to asthma severity, age, gender and use of preventive medications were similar within each group, suggesting that asthma severity, age, gender or use of a preventive medication had no effect on asthma perception (Table 2). These data confirmed the results of the individual analysis.

\section{Discussion}

The present study showed that asthma perception was inaccurate in a high proportion of asthmatic children, independently of clinical severity, age, gender or use of a preventive medication. Previous studies on both children and adults have shown that individual ability to perceive airway obstruction induced by bronchial provocation tests or occurring spontaneously varies substantially $(2,13,14)$. Some asthmatics may consider themselves symptom-free in the midst of an asthma attack or feel severe breathlessness during a mild exacerbation. The factors influencing the perception of asthma are probably numerous and not well established. Some studies reported the influence of circa-

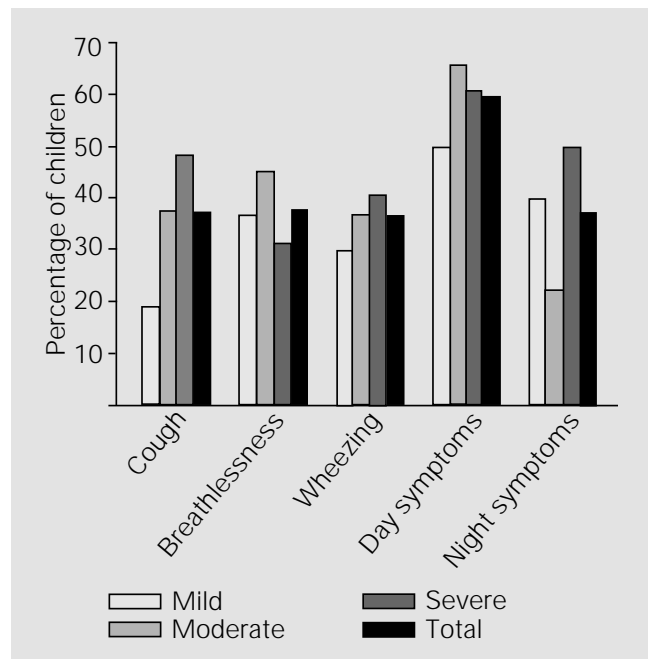

Figure 1. Percentage of children with a significant correlation between symptoms and peak expiratory flow (PEF), divided into three groups according to asthma severity. There was no influence of asthma severity on the percentage of children with a significant correlation between PEF values and cough (86 children studied, $P=0.09$ ), breathlessness $(\mathrm{N}=82, \mathrm{P}=0.52)$ wheezing $(\mathrm{N}=82, \mathrm{P}=0.74)$, nocturnal symptoms ( $\mathrm{N}=70$, $\mathrm{P}=0.10$ ) or total diurnal symptoms (cough, breathlessness and wheezing, $\mathrm{N}=87, \mathrm{P}=0.51$ ).

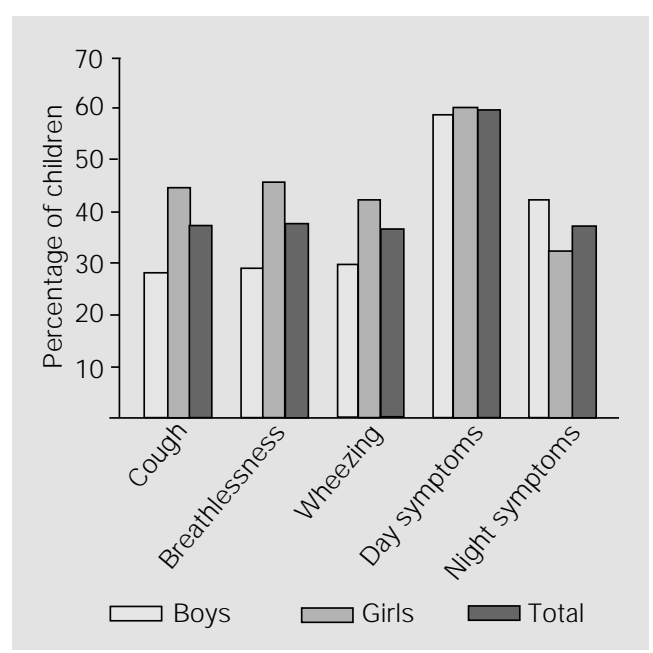

Figure 2. Influence of gender on the percentage of children that showed a significant correlation between peak expiratory flow values and symptoms $(P=0.12$, $0.12,0.24,0.89$ and 0.39 for cough, breathlessness, wheezing, daytime symptoms and nocturnal symptoms, respectively).

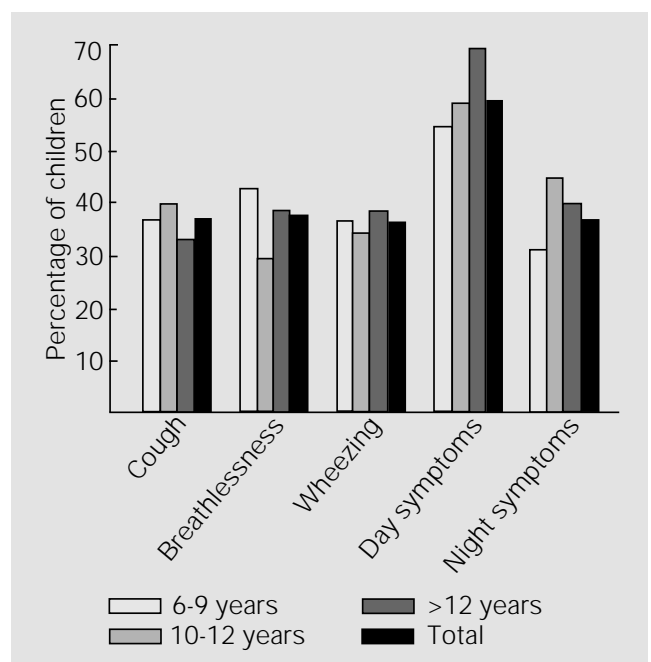

Figure 3. Influence of age on the percentage of children that showed a significant correlation between peak expiratory flow values and symptoms $(P=0.90$, $0.54,0.96,0.45$ and 0.45 for cough, breathlessness, wheezing, daytime symptoms and nocturnal symptoms, respectively). 
Figure 4. Influence of the use of preventive medicine (nedocromil, cromoglycate or beclomethasone) on the percentage of children that showed a significant correlation between peak expiratory flow values and symptoms $(P=0.08,0.16,0.14,0.08$ and 0.24 for cough, breathlessness, wheezing, daytime symptoms and nocturnal symptoms, respectively). dian rhythm (14), psychological factors such as negative emotions (15), and corticosteroid treatment $(16,17)$.

McFadden et al. (18) evaluated the relationship between PEF and symptoms in asthmatics recovering from an acute attack and reported that patients became asymptomatic when PEF was on average $40-50 \%$ of the predicted value. Rubinfield and Pain (19) found that $15 \%$ of patients were unable to sense the presence of marked airway ob-

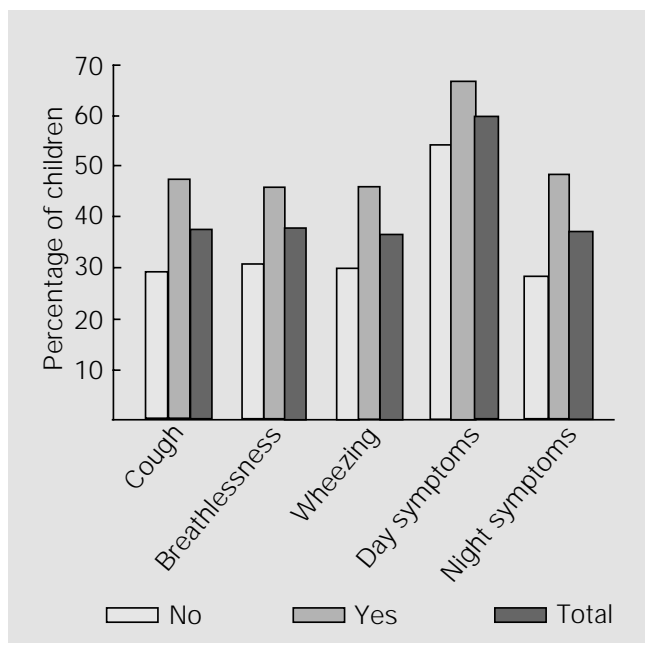

struction during methacholine-induced bronchoconstriction. Shim and William (9) suggested the concept of good and poor perceivers of airway obstruction and showed a good group correlation between perceived changes in airway obstruction from day to day and measured changes in peak flow. Sly et al. (20) studied 14 children and found that they also were unable to accurately predict their degree of airway obstruction. They also analyzed the accuracy of parental perceptions of their child's airway obstruction and found they were too unreliable. In the present study, we used a different approach than most of the previous studies. We considered accurate perceivers those children who presented a significant regression coefficient between PEF and symptoms. We observed that in $40 \%$ of the children studied there was no significant correlation between the presence of any diurnal symptom and PEF values and in $63 \%$ there was no correlation between nocturnal symptoms and PEF.

Some investigators have emphasized the influence of circadian rhythm on the accuracy of symptom perception. Pfeiffer et al.

Table 2. Multiple linear regression coefficients ( $/ / \mathrm{min})$ with peak expiratory flow rate as dependent variable and symptoms as independent variables.

\begin{tabular}{lcccc}
\hline Group & Cough & Wheezing & Breathlessness & Nocturnal symptoms \\
\hline $\begin{array}{l}\text { Total } \\
\text { Gender }\end{array}$ & $-11.14 \pm 0.87$ & $-14.47 \pm 0.88$ & $-13.21 \pm 0.97$ & $-14.10 \pm 1.20$ \\
$\quad$ Male & $-12.05 \pm 1.22$ & $-16.29 \pm 1.28$ & $-13.31 \pm 1.34$ & $-12.83 \pm 1.68$ \\
$\quad$ Female & $-10.00 \pm 1.24$ & $-12.50 \pm 1.21$ & $-12.88 \pm 1.41$ & $-15.18 \pm 1.69$ \\
Age range (years) & & & & \\
6-9 & $-10.25 \pm 0.97$ & $-12.27 \pm 1.10$ & $-12.57 \pm 1.20$ & $-13.20 \pm 1.49$ \\
10-12 & $-11.47 \pm 1.71$ & $-14.60 \pm 1.66$ & $-12.38 \pm 1.88$ & $-13.94 \pm 2.35$ \\
$>12$ & $-13.99 \pm 2.58$ & $-18.67 \pm 2.24$ & $-15.84 \pm 2.42$ & $-16.69 \pm 2.83$ \\
Preventer & & & & \\
$\quad$ No & $-11.55 \pm 1.31$ & $-16.21 \pm 1.36$ & $-13.98 \pm 1.37$ & $-14.11 \pm 2.78$ \\
$\quad$ Yes & $-10.22 \pm 1.07$ & $-13.37 \pm 1.07$ & $-13.04 \pm 1.27$ & $-14.65 \pm 1.49$ \\
Severity & $-10.42 \pm 1.61$ & $-12.49 \pm 1.74$ & $-17.36 \pm 2.66$ & $-6.90 \pm 1.68$ \\
$\quad$ Mild & $-8.42 \pm 1.34$ & $-14.06 \pm 1.57$ & $-8.62 \pm 1.68$ & $-3.79 \pm 1.40$ \\
$\quad$ Moderate & $-14.63 \pm 1.51$ & $-15.56 \pm 1.45$ & $-19.07 \pm 2.09$ & $-9.36 \pm 1.61$ \\
$\quad$ Severe & means \pm SEM.P<0.05 for all coefficients (multiple regression analysis).
\end{tabular}


(14) showed that the strongest correlation between dyspnea intensity and PEF occurred at 7 am and Weiss (21) reported that children complain more of breathlessness at night, irrespective of lung function. We found similar results for the percentage of children with good perception, i.e., $59.8 \%$ for diurnal symptoms and only $37.1 \%$ for nocturnal symptoms. Our observations suggest that symptom perception in asthma is better during the day.

Roisman et al. (16) reported that patient perception of bronchoconstriction induced by bradykinin is related to eosinophilic inflammation and to epithelial damage and could be improved by corticosteroid treatment. This observation was confirmed by Boulet et al. (17), who reported that patients using inhaled corticosteroids show a greater perception of methacholine-induced bronchoconstriction. In the present study, asthma perception was not significantly affected by the use of a preventive medication (most of the children on preventive treatment were receiving inhaled beclomethasone), although there was a clear tendency for children who used preventive medication to show better perception of symptoms. This discordant finding could be partially explained by the fact that we studied the perception of symptoms during spontaneous airway obstruction while these authors studied perception during induced bronchoconstriction. Moreover, Boudreau et al. (22) did not observe a significant correlation between the ability to sense breathlessness during induced and spontaneous bronchoconstriction.

Perceptual inaccuracies may be related to chronic inflammation and loss of epithelium, gradually affecting the afferent information (23). Consequently, the worst accuracy would be expected in severe asthma. Studies addressing this issue have come to discordant conclusions. Apter et al. (1) reported that patients with lower forced expiratory flow between $25 \%$ and $75 \%$ of the vital capacity $\left(\mathrm{FEF}_{25-75}\right)$ tended to be less accurate perceivers. Chetta et al. (24) found that poor perception was associated with asthma severity and Bijl-Hofland et al. (25) reported that low baseline forced expiratory volume in $1 \mathrm{~s}\left(\mathrm{FEV}_{1}\right)$ and high hyperresponsiveness were associated with a low perceptiveness of bronchoconstriction. In contrast, Pfeiffer et al. (14) concluded that good and poor perceivers did not differ in terms of the severity or duration of asthma and Fritz et al. (11) reported that children's perceptual accuracy of symptoms was not related to severity. We have also shown that children with mild asthma were as inaccurate in symptom perception as children with severe asthma.

In our analysis, we did not include children who had no variability of the symptom under study, since our purpose was to determine if there was a significant correlation between symptoms and PEF. However, the number of children excluded was very low (Figure 1). Only 48 (52\%) children had at least 90 consecutive days of observation, suggesting that the adherence to PEF monitoring decreases with time. We do not believe that this fact influenced the results since we did not observe significant differences between the groups of children who provided full and missing data with respect to asthma severity, age, sex or the number of accurate perceivers.

Teeter et al. (3) observed a significant but poor relationship between PEF and total asthma symptom score, but, when they analyzed individual symptoms, the only individual relationship of statistical significance was between PEF and wheezing. They suggested that, in adults, wheezing is the asthma symptom most predictive of the level of airway obstruction. According to our data, no special self-reported symptom was a better predictor of airway obstruction since all symptoms had similar correlation coefficients and all presented a statistical significant relationship with PEF.

Most studies performed on adults have shown that poor perceivers were not charac- 
terized as a distinct group based on gender, age or baseline $\mathrm{FEV}_{1}(1,3,14,24,26)$. These findings were confirmed in children by Fritz et al. (11) and in our study. On the other hand, Yoos and McMullen (10) reported that adolescents were more accurate perceivers than school-age children. There are no data directly addressing the age at which children can reliably monitor PEF. In the absence of reliable data, some authorities have adopted the position that PEF recordings should be interpreted with caution in children under the age of 7 or 8 , particularly during exacerbations of asthma (27). However, in our study the group of children aged 6 to 9 years had a similar percentage of accurate perceivers as the older children.

In spite of a poor relationship between symptoms and objective measures of respiratory dysfunction, decisions about treatment are largely based on symptoms recorded by the child and his/her parents. It is not easy to convince someone who has no symptoms to take a drug on a regular basis or to decrease medication when the patient does not report improvement. Charlton et al. (28) evaluated PEF and symptoms-only self-management plans for asthma control and concluded that symptoms-only self-management can be effective in general practice. This may not be the case for some children, especially those with severe asthma, since they have a higher risk for deterioration. However, we were unable to demonstrate that poor perceivers are more common among severe asthmatics as it might be expected due to habituation to chronic and more severe airway obstruction. In fact, it still remains unclear why some asthmatics are capable of accurately perceiving airway obstruction whereas others are not.

The present results suggest that asthma perception is inaccurate in a good proportion of asthmatic children regardless of asthma severity, age, use of preventive medication or gender. Children will benefit from regular monitoring of their pulmonary function rather than relying exclusively on their own perception of asthma severity. It is very important to find ways to improve the adherence to PEF monitoring, mainly in children with more severe forms of asthma.

\section{Acknowledgments}

The authors thank Dr. Arden C. Pope III, from the Economics Department, Brigham Young University, Provo, Utah, for helpful advice concerning statistical analysis.

\section{References}

1. Apter AJ, Affleck G, Reisine ST, Tennen HA, Barrows E, Wells M, Willard A, Zu A $\&$ Wallack RL (1997). Perception of airway obstruction in asthma: Sequential daily analyses of symptoms, peak flow rate, and mood. J ournal of Allergy and Clinical Immunology, 99: 605-612.

2. Sly PD (1997). Relationship between change in PEF and symptoms: questions to ask in pediatric clinics. European Respiratory J ournal, 10: 80S-83S.

3. Teeter J G \& Bleecker ER (1998). Relationship between airway obstruction and respiratory symptoms in adult asthmatics. Chest, 113: 272-277.

4. Creer TL (1983). Response: self-management psychology and the treatment of childhood asthma. J ournal of Allergy and Clinical Immunology, 72: 607-610.

5. National Institutes of Health (NIH) (1992). International Consensus Report on Diagnosis and Treatment of Asthma. Bethesda, MD, USA, Publication No. 923091.

6. National Institutes of Health (NIH) (1995). Global Initiative for Asthma (GINA). Bethesda, MD, USA, Publication No. 953659.

7. National Institutes of Health (NIH) (1997). Expert Panel Report 2: Guidelines for the Treatment and Management of Asthma. Bethesda, MD, USA, Publication No. 974051-a.

8. Reeder P, Dolce J J, Duke L, Raczynski
JM \& Bailey WC (1990). Peak flow meters: Are they monitoring tools or training devices? J ournal of Asthma, 27: 219227.

9. Shim CS \& William MH (1980). Evaluation of severity of asthma: patients versus physician. American J ournal of Medicine, 68: 11-13.

10. Yoos HL \& M CMullen A (1999). Symptom perception and evaluation in childhood asthma. Nursing Research, 48: 2-8.

11. Fritz GK, Klein RB \& Overholser J C (1990). Accuracy of symptom perception in childhood asthma. J ournal of Developmental and Behavioral Pediatrics, 11: 69-72.

12. Reddel HK, Salome CM, Peat J \& Woolcock AJ (1995). Which index of peak expi- 
ratory flow is most useful in the management of stable asthma? American J ournal of Respiratory and Critical Care Medicine, 151: 1320-1325.

13. J ames AL, Caroll N, De Klerk N, Elliot J , Musk AW \& Ryan G (1998). Increased perception of airway narrowing in patients with mild asthma. Respirology, 3: 241245.

14. Pfeiffer C, Marsac J \& Lockhart A (1989). Chronobiological study of the relationship between dyspnea subjects. Clinical Science, 77: 237-244.

15. J anson C, Bjornsson E, Hetaa J \& Boman $G$ (1994). Anxiety and depression in relation to respiratory symptoms and asthma. American J ournal of Respiratory and Critical Care Medicine, 149: 930-934.

16. Roisman GL, Peiffer C, Lacronique J G, Le Cae A \& Dusser DJ (1995). Perception of bronchial obstruction in asthmatic patients. Relationship with bronchial eosinophilic inflammation and epithelial damage and the effect of corticosteroid treatment. J ournal of Clinical Investigation, 96: 12-21.

17. Boulet LP, Turcotte H, Carteir A, Milot J, Cote J , Maol J L \& Laviolette M (1998).
Influence of beclomethasone and salmeterol on the perception of methacholineinduced bronchoconstriction. Chest, 114: 373-379.

18. McFadden ER, Kiser R \& Degroot WJ (1973). Acute bronchial asthma: relations between clinical and physiologic manifestations. New England J ournal of Medicine, 288: 221-225.

19. Rubinfield AR \& Pain MCF (1976). The perception of asthma. Lancet, 1: 882-884.

20. Sly PD, Landau LI \& Weymouth R (1985). Home recording of peak flow rates and perception of asthma. American J ournal of Diseases of Children, 139: 479-482.

21. Weiss JH (1966). Moodstates associated with asthma in children. J ournal of Psychosomatic Research, 10: 267-270.

22. Boudreau $D$, Styhler $A$, Gray-Donald $K \&$ Martin J G (1995). A comparison of breathlessness during spontaneous asthma and histamine-induced bronchoconstriction. Clinical and Investigative Medicine, 18: 25-32.

23. Barnes PJ (1986). State of art: neural control of human airways in health and disease. American Review of Respiratory Disease,134: 1289-1302.
24. Chetta A, Guerra G, Foresi A, Del Donno $M$, Chittolini B, Malorgio R, Castagnaro A \& Olivieri D (1998). Personality profiles and breathlessness perception in outpatients with different gradings of asthma. American J ournal of Respiratory and Critical Care Medicine, 157: 116-122.

25. Bijl-Hofland ID, Cloosterman SG, Folgering HT, Akkermans RP \& van Schayck CP (1999). Relation of the perception of airway obstruction to the severity of asthma. Thorax, 54: 15-19.

26. Kendrick $A H$, Higgs $C M$, Whitfield $M J \&$ Laszlo G (1993). Accuracy of perception of severity of asthma: patients treated in general practice. British Medical J ournal, 307: 422-424

27. Henry R, Sly P, Godfrey S, Van Asperen P, Le Souef PN, Smith G, Robertson I, Robertson C \& Phelan P (1991). Assessment and treatment of asthma in childhood. J ournal of Paediatrics and Child Health, 27: 218-220.

28. Charlton I, Charlton G, Broomfield J \& Mullee M (1990). Evaluation of peak flow and symptoms only plans for control of asthma in general practice. British Medical J ournal, 301: 1355-1359. 